\title{
Infant Mortality, Non-AIDS
}

National Cancer Institute

\section{Source}

National Cancer Institute. Infant Mortality, Non-AIDS. NCI Thesaurus. Code C18850.

infant death due to causes other than AIDS 